\title{
Radiation induced COX-2 expression and mutagenesis at non-targeted lung tissues of gpt delta transgenic mice
}

\author{
Y Chai ${ }^{1}, \mathrm{G} \mathrm{M} \mathrm{Calaf}{ }^{2,3}, \mathrm{H}$ Zhou $^{2}$, S A Ghandhi ${ }^{2}, \mathrm{CD}$ Elliston ${ }^{2}, \mathrm{G} \mathrm{Wen}{ }^{2}, \mathrm{~T} \mathrm{Nohmi}^{4}, \mathrm{~S} \mathrm{~A} \mathrm{Amundson}{ }^{2}$ and \\ $\mathrm{TKHei}{ }^{*, 1,2}$
}

${ }^{1}$ Department of Environmental Health Sciences, Mailman School of Public Health, Columbia University, New York, NY, USA; ${ }^{2}$ Center for Radiological Research, College of Physicians and Surgeons, Columbia University, New York, NY, USA; ${ }^{3}$ Instituto de Alta Investigación, Universidad de Tarapacá, Arica, Chile and ${ }^{4}$ Division of Genetics and Mutagenesis, National Institute of Health Science, Tokyo, Japan

Background: Although radiation-induced bystander effects have been confirmed using a variety of endpoints, the mechanism(s) underlying these effects are not well understood, especially for in vivo study.

Methods: A $1-\mathrm{cm}^{2}$ area $(1 \mathrm{~cm} \times 1 \mathrm{~cm})$ in the lower abdominal region of gpt delta transgenic mice was irradiated with $5 \mathrm{~Gy}$ of $300 \mathrm{keV} \mathrm{X}$-rays, and changes in out-of-field lung and liver were observed.

Results: Compared with sham-treated controls, the Spi ${ }^{-}$mutation frequency increased 2.4-fold in non-targeted lung tissues at $24 \mathrm{~h}$ after partial body irradiation (PBIR). Consistent with dramatic Cyclooxygenase 2 (COX-2) induction in the non-targeted bronchial epithelial cells, increasing levels of prostaglandin, together with 8-hydroxydeoxyguanosine, in the out-of-field lung tissues were observed after PBIR. In addition, DNA double-strand breaks and apoptosis were induced in bystander lung tissues after PBIR.

Conclusion: The PBIR induces DNA damage and mutagenesis in non-targeted lung tissues, especially in bronchial epithelial cells, and COX-2 has an essential role in bystander mutagenesis.

Ionising radiation is a well-known clastogen that induces a range of DNA damages in vitro and in vivo (Sankaranarayanan, 1991). Besides the direct effects of ionising radiation in targeted cells, tissue culture experiments have shown that a series of biological effects can be induced in neighbouring, non-irradiated cells after irradiation of a portion of cells in a confluent monolayer. These effects include apoptosis (Prise et al, 1998), mutagenesis, genetic instability and inflammatory response (Hei, 2006). The response in the non-targeted cells or tissues by signals from direct irradiation is called radiation-induced bystander effect. Studies conducted using a signal transduction pathway-specific cDNA array suggested that cyclooxygenase 2 (COX-2; also known as prostaglandin synthase 2 or PTGS2) is consistently upregulated by more than three-fold in bystander cells (Zhou et al, 2005). Furthermore, treatment of bystander cells with NS-398, a specific inhibitor of COX-2, reduces mutagenesis by more than six-fold over the corresponding controls. Cyclooxygenase- 2 can be induced by a variety of cytokines including tumour necrosis factor- $\alpha$, transforming growth factor- $\beta$, interleukin-1, interleukin-6 and insulin-like growth factor (Zhou et al., 2008). Importantly, extensive data indicates a link between genetic instability and expression of COX-2 (Sudbo et al, 2003). Whereas COX-2 is weakly expressed in most benign tumours and normal cells, it is overexpressed in malignant pheochromocytomas (Salmenkivi et al, 2001). Induction of COX-2 by the carcinogen benzo[ $\alpha]$ pyrene diolepoxide (BPDE) may induce mutagenic effects to facilitate the development of skin 
cancer (Ouyang et al, 2007). Studies in mouse epidermal cells have shown that BPDE enhances COX-2 expression through MAPK/ $\mathrm{AP}-1$ and IKK/NF- $\kappa \mathrm{B}$, and ultimately causes the genetic mutations (Song et al, 2005).

Although it is conceptually possible that bystander effects are linked to radiation-induced secondary carcinogenesis, there are few experimental data to evaluate bystander effects in vivo (Chai and Hei, 2008). Abscopal/non-targeted effects are used to describe systemic effects that were observed at non-irradiated sites in animals after treatment with localised irradiation. An abscopal effect, such as inhibition of tumour growth in non-targeted regions has been demonstrated in several clinical observations and experimental results, which is described as bystander effect-like phenomenon (Morgan and Breit, 1995). With particular relevance to cancer risk, oncogenic effects have been observed in the nontargeted cerebellum of radiosensitive Patched-1 (Ptch1) heterozygous mice, when only the lower halves of animals were irradiated by X-rays (Mancuso et al, 2008).

In the present study, we examined in vivo DNA damage and mutagenesis in the out-of-field lung and liver tissues of $g p t$ delta transgenic mice after a 5-Gy dose of X-rays delivered to the lower abdomen of otherwise shielded animals. We further investigated the induction of COX-2 and its role in the observed mutations in the non-targeted lung tissue.

\section{MATERIALS AND METHODS}

Animal model and irradiation procedure. The gpt delta transgenic mice were obtained from Dr Takehiko Nohmi of the National Institute of Health Sciences in Japan (Nohmi et al, 1996). The gpt delta transgenic mouse model has been used to detect different types of mutations in vivo by various types of irradiation including X-rays, $\gamma$-rays and heavy ions (Masumura et al, 2002). Eight- to 12-week-old male and female mice were used. Each group consisted of three animals. All experiments were performed in compliance with the institutional regulations and guidelines for animal experimentation. For the partial body irradiation (PBIR) group (also called bystander group), each animal was anaesthetised by intraperitoneal injection of $0.3 \mathrm{ml} 2.5 \%$ Tribromoethanol (Kiatchoosakun et al, 2001). The anaesthetised animal was laid face-up and fixed on a platform designed by the Columbia University CRR Design and Instrument Shop (New York, NY, USA) (Figure 1A). A $1-\mathrm{cm}^{2}(1 \mathrm{~cm} \times 1 \mathrm{~cm})$ area of the lower abdomen of the animal was chosen and marked for the irradiation. A set of lead shields were laid upon the animal in a manner that allowed only the marked area to remain uncovered. All of the mice in the PBIR groups received a 5-Gy dose of $300 \mathrm{keV}$ X-rays at a dose rate of $3.6 \mathrm{~Gy} \mathrm{~min}^{-1}$. Multiple groups of animals were used to study the kinetics of bystander responses in vivo after lower abdomen irradiation. Animals were euthanized at a series of time points (from 1 to $72 \mathrm{~h}$ ) after PBIR. Lung and liver tissues were collected and processed for further biomedical and molecular studies. A portion of each tissue was frozen in liquid nitrogen, whereas the rest of each tissue was fixed in 10\% formalin. Animals were whole-body irradiated (WBIR) with either $5 \mathrm{~Gy}$ X-rays as WBIR group, or 6 cGy X-rays as scattering radiation group. Two additional groups were used as controls. One group was irradiated with a single $5 \mathrm{~Gy}$ dose of X-rays under a $2.5-\mathrm{cm}$ thick lead shielding that covered the whole body. Another group was shamtreated as non-irradiated control mice (CTRL). There was no significant difference in the tested endpoints between these two groups, so only the CTRL group was shown in this study.

Measurement of scattering dose. Metal oxide semiconductor field-effect transistor (MOSFET) dosimeters (Best Medical Inc, Ottawa, ON, Canada) were used to measure the scattering doses in the internal non-targeted organs such as livers and lungs. Multiple MOSFET dosimeters were inserted in different parts of lungs and livers of anaesthetised animals and one dosimeter was placed in the targeted area before exposure to $5 \mathrm{~Gy}$ of X-rays. A calibration factor for the MOSFET was determined by recording the detector response in an open area in millivolts $(\mathrm{mV})$ and normalising to the exposure dose (5 Gy). The scattering dose in each part of examined organs was converted from the reading of each detector using the calibration factor (Figure 1B). The measured dose at either the liver or lung tissues after irradiation of the lower part of the abdomen with a single $5 \mathrm{~Gy}$ dose of X-rays was less than $6 \mathrm{cGy}(5.3 \mathrm{cGy}$ in liver, $4.9 \mathrm{cGy}$ in lung). Consequently, WBIR with $6 \mathrm{cGy}$ of X-rays was used as a scattering radiation control (WBIR $6 \mathrm{cGy}$ ).

Western blot analysis. Cell lysates (50 $\mu$ g protein) were resolved on $4-12 \%$ gradient gel by SDS-PAGE (Invitrogen, Grand Island, NY, USA) and processed according to standard protocols. The PVDF membranes were immunoblotted with anti-COX-2 (Cayman, Ann Arbor, MI, USA) and anti- $\beta$-actin (Sigma, St Louis, MO, USA) antibodies, respectively. The secondary antibodies were conjugated to horseradish peroxidase; signals were detected using the enhanced chemiluminescence system (Thermo Scientific, Waltham, MA, USA). The band of protein expression was quantified by Image $\mathrm{J}$ software and normalised to the $\beta$-actin expression level.

Immunohistochemistry staining. Immunohistochemistry staining was performed with various primary antibodies including COX-2 (Cayman), 8-hydroxydeoxyguanosine (8-OHdG; Abcam, Cambridge, MA, USA), cleaved Caspase-3 (Cell Signaling, Danvers, MA, USA), and 53BP1 (Novus Biologicals, Litteton, CO, USA) as previously described (Calaf et al, 2008). The slides were analysed using an Olympus CX31 microscope connected with
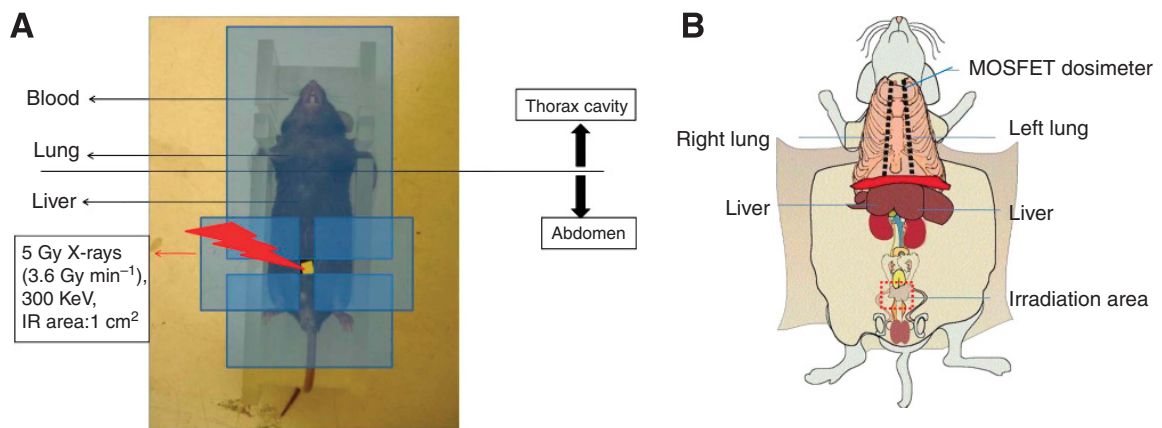

Figure 1. Irradiation setup for shielded irradiation and measurement of scattering doses in non-targeted organs. (A) A $1-\mathrm{cm}{ }^{2}(1 \mathrm{~cm} \times 1 \mathrm{~cm})$ area of the lower abdomen of a gpt delta transgenic mouse placed in a chamber was irradiated with 5 Gy of X-rays with the rest of body shielded by lead shielding. (B) Multiple MOSFET dosimeters were inserted into the lungs, livers and targeted area of gpt mouse to measure the scattering doses. 
a Motic MC Camera (2.0 megapixel; MC2001interface, Sterling Heights, MI, USA). Paint Shop Pro (Mountain View, CA, USA) was used to measure the protein expression level. The freehand selection tool was used to select the sample area to be measured (therefore, there is NO actual cell number involved, merely the area selected for measurement). An arbitrary threshold of 125 (nonspecific staining level) was applied to the random selected area on the tissue as background. This area was then inverted to measure the mean of the lightness channel. The value obtained in this procedure was used as a relative grade of luminescence to quantify the samples and to generate the graph. The data were expressed as the mean \pm s.e.m. of the relative grade of luminescence obtained from each slide.

Prostaglandin enzyme immunoassay. Levels of two major isoforms of prostaglandin, prostaglandin $\mathrm{E}_{2} \quad\left(\mathrm{PGE}_{2}\right)$ and 8-iso prostaglandin $\mathrm{F}_{2}$ (8-iso $\mathrm{PGF}_{2}$ ) in the tissues and plasma were determined by enzyme immunoassay (Assay Designs Inc., Ann Arbor, MI, USA) according to the manufacturer's instructions.

Genomic DNA extraction and in vitro packaging of DNA. High molecular-weight genomic DNA was extracted from the lungs and livers of animals using the Recover Ease DNA Isolation Kit (Invitrogen). Lambda EG10 phages were rescued using Transpack Packaging Extract (Invitrogen) according to manufacturer's instructions.

$\mathrm{Spi}^{-}$mutation analysis and mutant characterisation. The mutant frequency (MF) at red/gam loci was determined by $\mathrm{Spi}^{-}$ selection assay as described previously (Lee et al, 2005; Nohmi et al, 1996; Nohmi and Masumura, 2004). Mutation frequencies were calculated by comparing the titration and number of confirmed mutant plaques. To determine the mutation region, the phage DNA of selected plaques were collected and subjected to DNA sequence and PCR analysis as described previously (Horiguchi et al, 2001; Masumura et al, 2003).

Statistical analysis. All data were expressed as mean \pm s.e.m. Differences between groups were tested for statistical significance using a Student's $t$-test. A $P$-value $<0.05$ denote the presence of a statistically significant difference.

\section{RESULTS}

Mutagenesis by $\mathrm{Spi}^{-}$assay in non-targeted lung tissues after lower abdominal irradiation. Radiation-induced bystander effects have been known to induce chromosomal deletions and loss of genes in vitro (Zhou et al, 2000) and in vivo (Mancuso et al, 2008). We examined larger size mutations in bystander lung tissues using the $\mathrm{Spi}^{-}$assay, which is distinct from the $\mathrm{gpt}$ assay that detects primarily site mutations (Nohmi and Masumura, 2005). In this study, relative to controls, $\mathrm{Spi}^{-} \mathrm{MF}$ in non-targeted lung of PBIR mice increased 2.4-fold by $24 \mathrm{~h}$ after $5 \mathrm{~Gy}$ irradiation of the lower abdomen (Figure 2). The MF at $72 \mathrm{~h}$ after PBIR was still elevated, but was only 1.7 -fold relative to the control level. At $24 \mathrm{~h}$ after treatments, the MF in lung tissues of animals exposed to a 6cGy dose of simulated scattering dose was not significantly different from the spontaneous MF in non-irradiated lungs of control animals. On the other hand, WBIR with 5 Gy of X-rays induced a three-fold increase in the MF in irradiated lung tissue. The PCR analysis of selected colonies showed different mutation spectra between the control and PBIR groups (Table 1). Surprisingly, 70\% of mutations from bystander lung tissues were deletions larger than $2 \mathrm{~kb}$ in size compared with $13 \%$ found in the control group. The frequency of large deletions $(>2 \mathrm{~kb})$ in bystander lungs was 19 times higher relative to the control level (CTRL vs PBIR $5 \mathrm{~Gy}, 0.37 \times 10^{-6}$ vs $\left.4.84 \times 10^{-6}\right)$. However, the frequency of point mutations and mutations less than $2 \mathrm{~kb}$ in size decreased

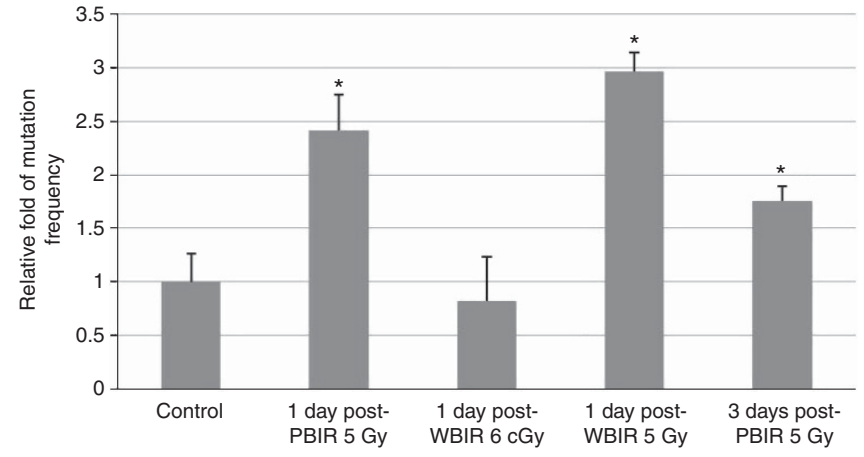

Figure 2. Mutant frequency (MF) by $\mathrm{Spi}^{-}$assay in bystander lung tissues. Relative fold change of Spi ${ }^{-}$MF in bystander lung tissues at 24 and $72 \mathrm{~h}$ after PBIR compared with control group. The WBIR with $5 \mathrm{~Gy}$ but not with scattering dose (6 cGy) increased Spi- MF in lung tissues at $24 \mathrm{~h}$ after irradiation. Statistical significance of the difference in MF between control and irradiation groups is marked with asterisks ( ${ }^{*} P<0.05$, Student's $t$-test). Error bars for quantification of relative Spi MF in each group indicate the s.e.m. for three independent animals.

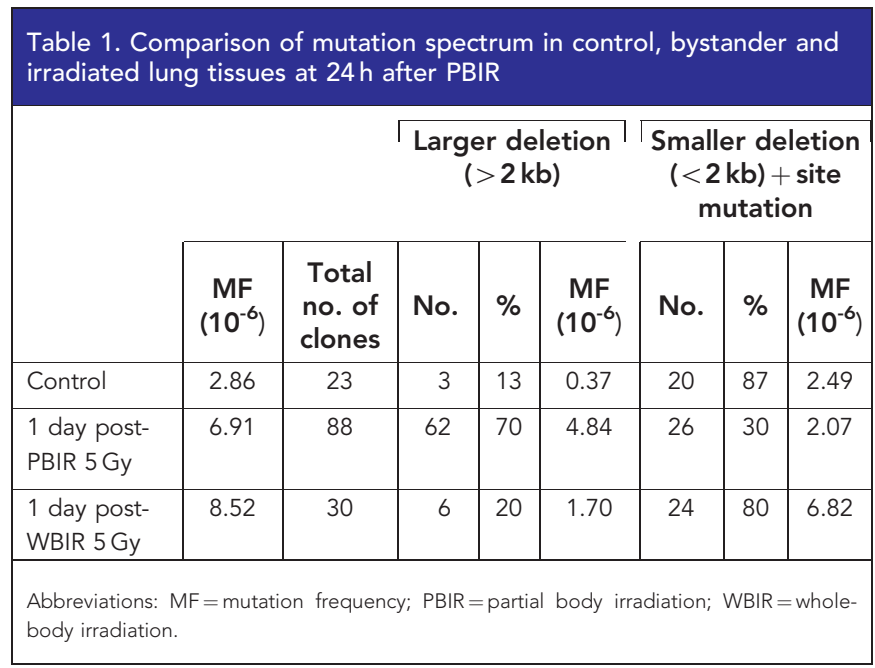

marginally in bystander lung tissues (CTRL vs PBIR $5 \mathrm{~Gy}$, $2.49 \times 10^{-6}$ vs $\left.2.07 \times 10^{-6}\right)$. In contrast to bystander lung tissues, the mutation spectrum analysis shows most of mutations in irradiated lung tissues are smaller size mutations, which occur at higher frequency than the control group as well (CRTL vs WBIR $5 \mathrm{~Gy}, 2.49 \times 10^{-6}$ vs $\left.6.82 \times 10^{-6}\right)$. After analysing all of the mutants, we did not find any hot spot mutation regions.

Lower abdominal irradiation induces COX-2 expression in bronchial epithelial cells of non-targeted lung tissues. We examined the protein level of COX-2 in bystander lung tissues of male animals at a series of time points after PBIR with $5 \mathrm{~Gy}$ of $\mathrm{X}$-rays. Cyclooxygenase 2 was induced at $1 \mathrm{~h}$ after irradiation and steadily increased within the first $24 \mathrm{~h}$ (Figure $3 \mathrm{~A}$ ); by $72 \mathrm{~h}$, it decreased to basal level. Densitometry analyses showed that protein levels of COX-2 at the peak increased more than 20-fold relative to un-irradiated controls (Figure 3B). Measurement of mRNA level of COX-2, determined by qRT-PCR, showed a similar tendency of induction as the protein product. The maximum level peak observed was a 10 -fold change at $3 \mathrm{~h}$ after irradiation, which gradually decreased to basal level by $48 \mathrm{~h}$ after treatment. We also examined female animals but found no gender differences in the bystander response (Figures 3C and D). Both female and male animals showed a similar induction peak of COX-2 at $24 \mathrm{~h}$ after irradiation, but the male animals had a higher induction level. 
Therefore, the remaining studies were conducted using male animals. At $24 \mathrm{~h}$ after treatment, whole body exposure to $6 \mathrm{cGy}$ of $\mathrm{X}$-rays did not result in an induction of COX-2, whereas WBIR with 5 Gy of X-rays induced a similar level of COX-2 as the PBIR groups (Figure 3A). This difference excludes the possibility that the induction of COX-2 in lung tissues was mediated by scattering radiation after PBIR.

Using immunohistochemical staining, we identified strong upregulation of COX-2 in lung tissues after PBIR. Interestingly,
COX-2 was found to be unevenly distributed in whole lung tissues, being predominantly localised in lung bronchial epithelial cells rather than the stromal cells. Quantification of COX-2 staining in lung bronchial epithelial cells showed a 30 -fold increase in the PBIR group relative to the control group, but only $\sim 7$-fold increase in the WBIR groups (Figure 3E and F). In contrast, there was no significant difference in the total expression levels of COX2 , as determined by western blotting in whole-lung tissues between PBIR and WBIR (Figure 3A).

A

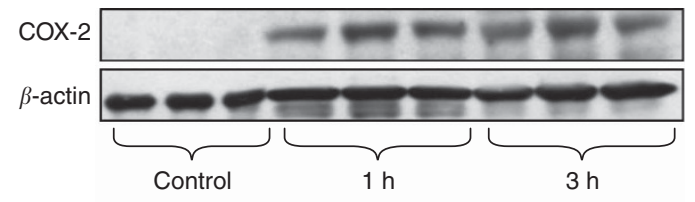

coX-2

$\beta$-actin

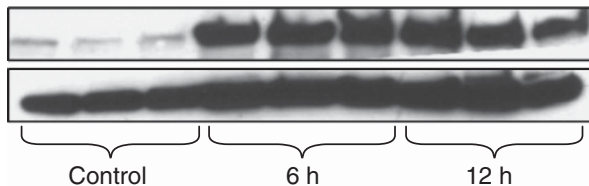

cox-2

$\beta$-actin
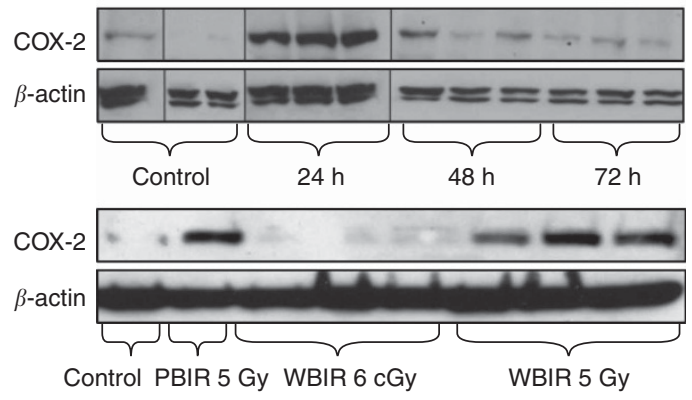

B1

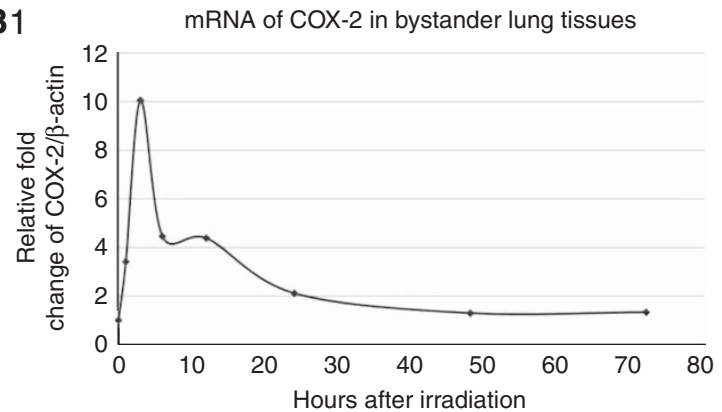

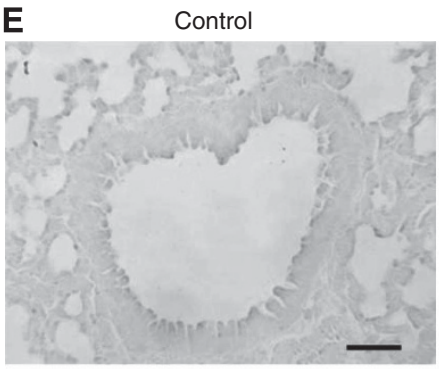

PBIR 5 Gy

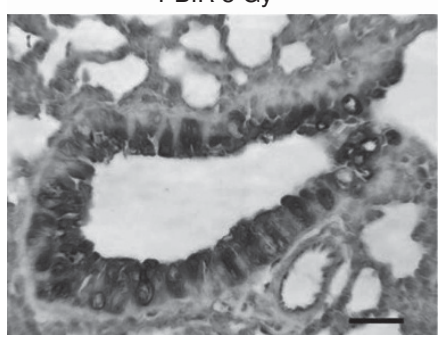

C Female

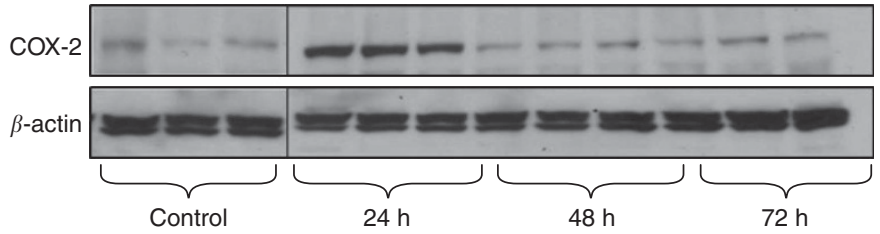

D
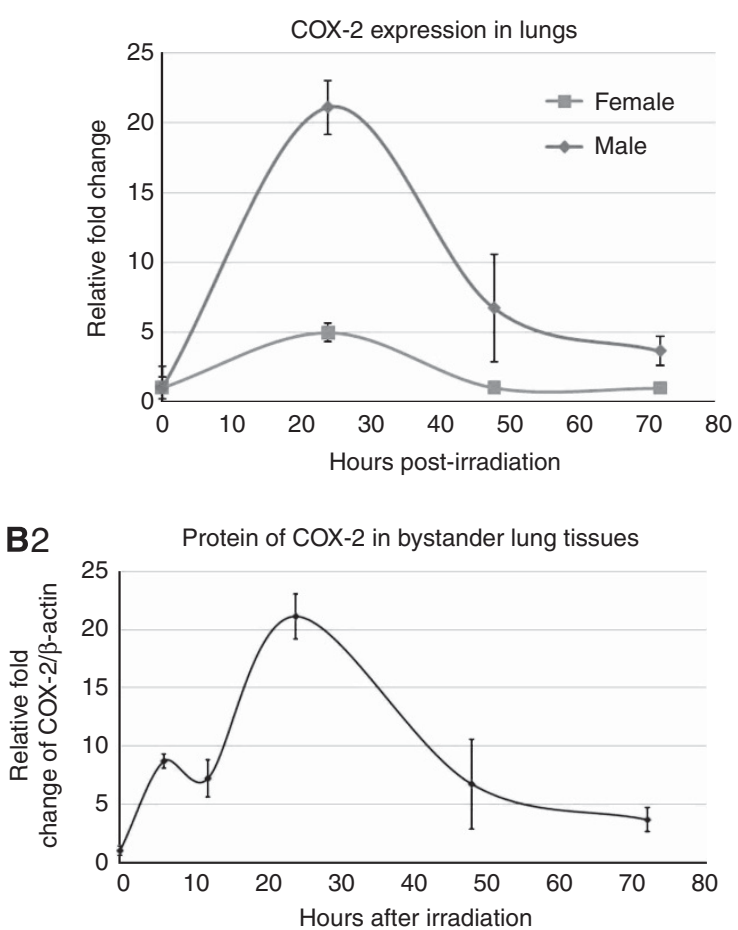

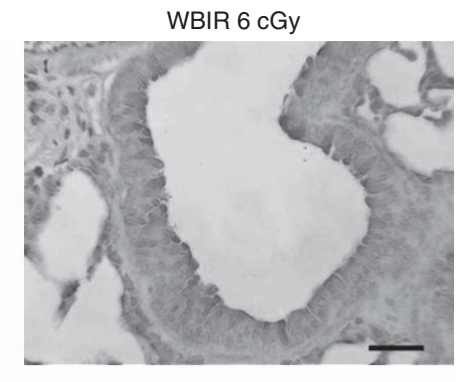

WBIR 5 Gy

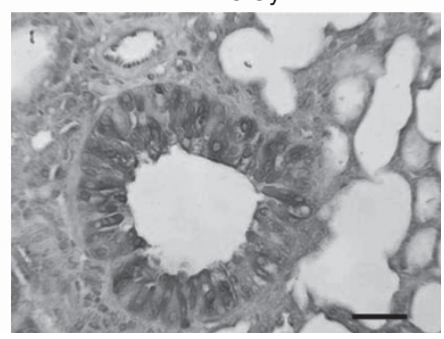

$\mathbf{F}$

COX-2 expression in lung bronchial epithelial cells

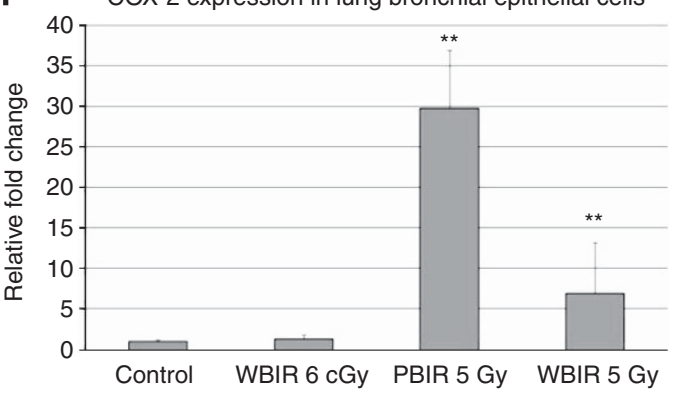


Lower abdominal irradiation induced prostaglandin production and oxidative DNA damage in out of field lung tissues. Cyclooxygenase 2 catalyses arachidonic acid to produce prostaglandin $\left(\mathrm{PGE}_{2}\right.$ and $\left.\mathrm{PGF}_{2}\right)$ in vitro and in vivo (Famaey, 1997). We examined the levels of $\mathrm{PGE}_{2}$ (Gardner et al, 2003) and 8-iso $\mathrm{PGF}_{2}$ (Mitchell et al, 1994), the two major isoforms of prostaglandin products of COX-2 enzyme activity, in bystander lung tissues at $24 \mathrm{~h}$ after PBIR with $5 \mathrm{~Gy}$ of X-rays, which was the peak time for

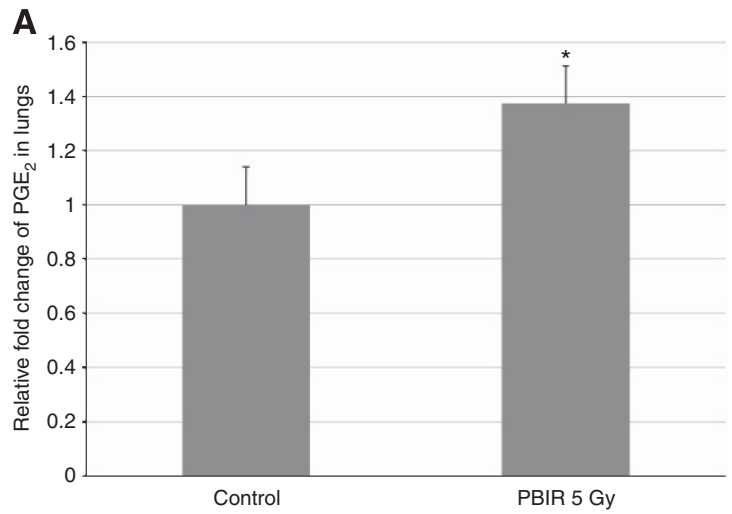

C
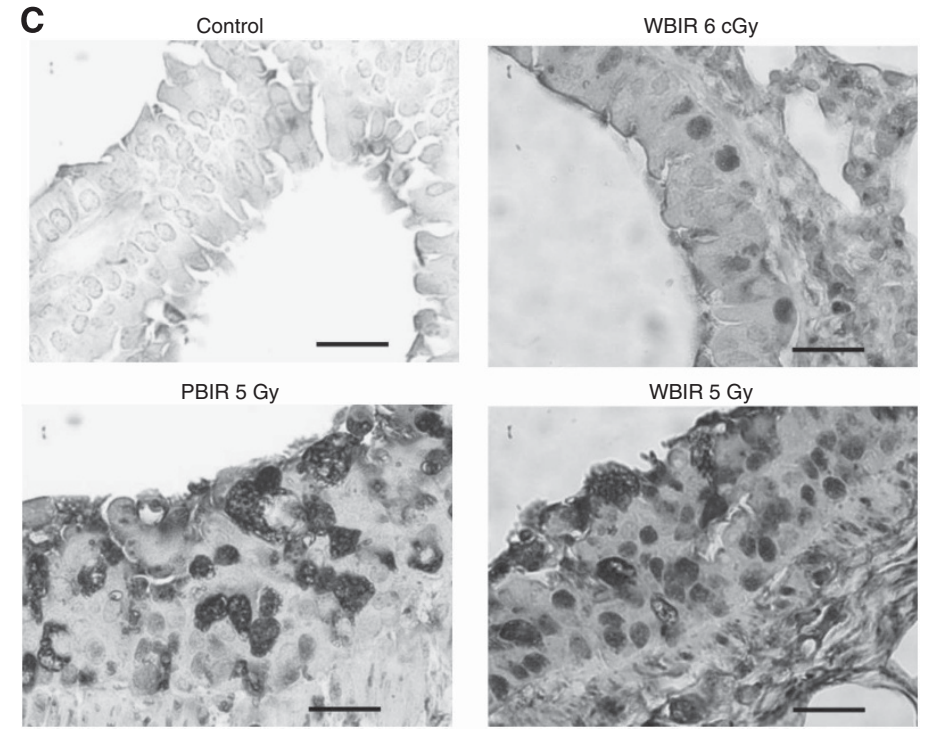

WBIR 5 Gy

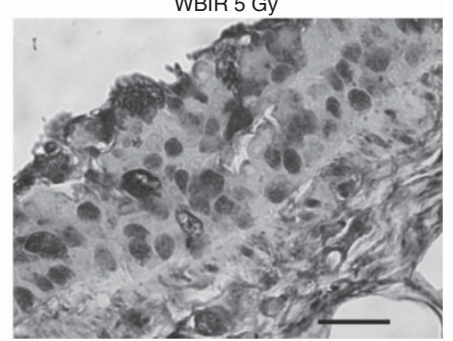

B

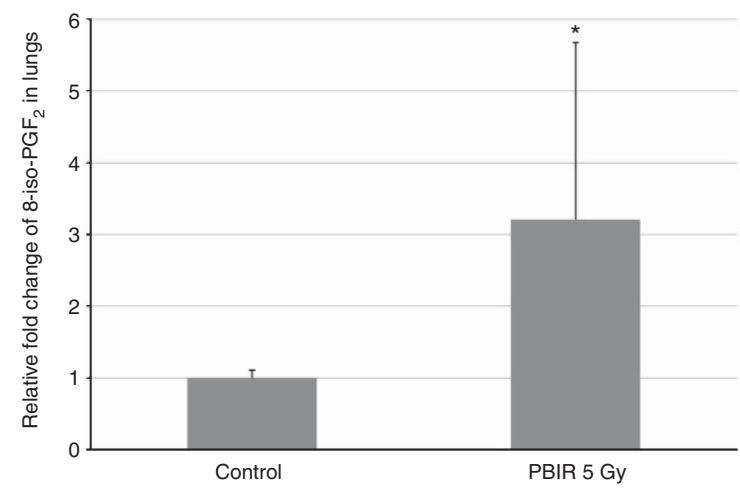

$\mathbf{D}_{1}$

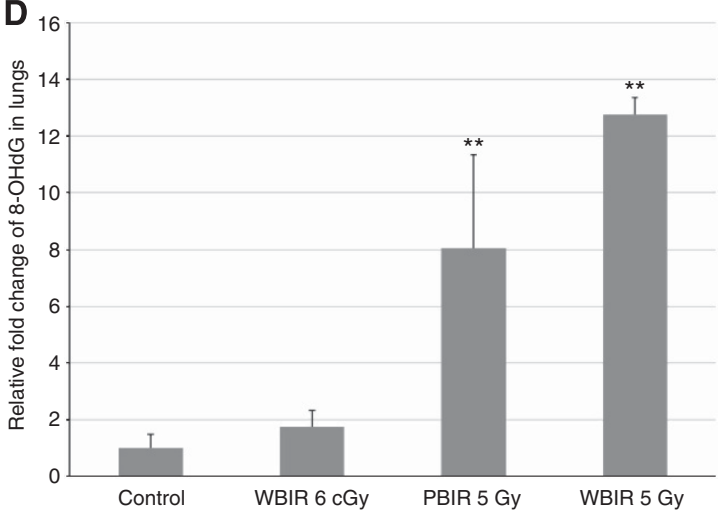

Figure 4. Partial body irradiation (PBIR) induced prostaglandin production and oxidative DNA damage in bystander lung tissues. Compared with control animals, two isoforms of prostaglandin, $\mathrm{PGE}_{2}(\mathbf{A})$ and 8-iso $\mathrm{PGF}_{2}(\mathbf{B})$, were elevated in bystander lung tissues at $24 \mathrm{~h}$ after irradiation. (C) The PBIR induced oxidative DNA damage in bystander lung tissues. One representative microscopic field of staining of 8-OHdG, oxidative DNA damage marker in lung tissues of each group at $24 \mathrm{~h}$ after irradiation; $\times 100$ magnification. (D) Quantification of 8-OHdG staining intensity in microscopic fields of each group under $\times 100$ magnification. Bar represents $20 \mu \mathrm{m}$. Statistical comparison between control and irradiation groups marked with asterisks ( $* P<0.05, * * P<0.01$, Student's $t$-test). Error bars for prostaglandin level indicate the s.e.m. for three independent mice. Error bars for quantification of $8-\mathrm{OHdG}$ staining in each group indicate the s.e.m. for 20 independent microscopic fields from three different mice.

Figure 3. Irradiation of the lower abdomen induced COX-2 expression in bystander lung tissues, especially bronchial epithelial cells. (A) Western blot analyses of COX-2 levels in lung tissues at a series of time points (1-72 h) after PBIR with 5 Gy of X-rays. Each group consists of three individual adult male animals. The WBIR with 5 Gy but not with a scattering dose (6 cGy) induced COX-2 expression in lung tissues at $24 \mathrm{~h}$ after irradiation. One representative animal from the control and PBIR 5 Gy groups were used for comparison. Each lane represents an individual animal. (B) Quantification of relative fold change of mRNA (B1) and protein (B2) levels of COX-2 relative to $\beta$-actin of each animal at a series of time points after irradiation. RNA isolation and mRNA measurements were conducted as previously described (Ivanov et al, 2010). Error bars indicate the s.e.m. for three independent mice. (C) COX-2 was induced in bystander lung tissues of female animals at a series of time points after 5 Gy X-rays PBIR. (D) Quantification of COX-2 protein levels in bystander lung tissues at a series of time points after irradiation. (E) Immunostaining analyses indicate that COX-2 is predominantly localised in bystander lung bronchial epithelial cells at $24 \mathrm{~h}$ after PBIR. A representative microscopic field of control, whole body exposure to 6 cGy (WBIR 6 cGy) or 5 Gy (WBIR 5 Gy), and partial body exposure to 5 Gy (PBIR 5 Gy) under $\times 40$ magnification. Bar represents $50 \mu \mathrm{m}$. (F) Quantification of COX-2 staining intensity is conducted in lung bronchial epithelial cells microscopic fields for each experimental group. Statistical comparison between control and irradiation groups marked with asterisks $\left({ }^{\star} P<0.05, * \star P<0.01\right.$, Student's t-test). Error bars indicate the s.e.m. for 20 independent microscopic fields from 3 different mice. 

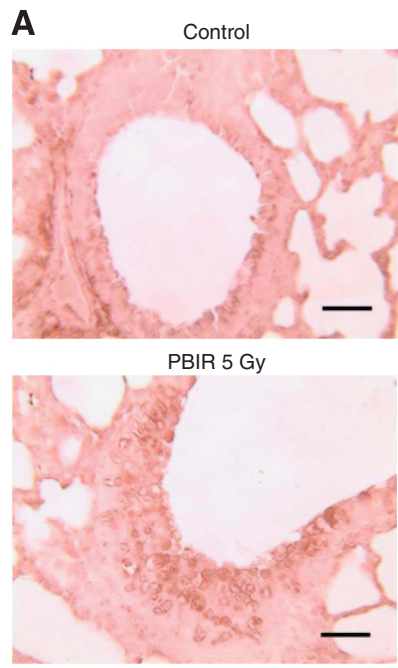

B

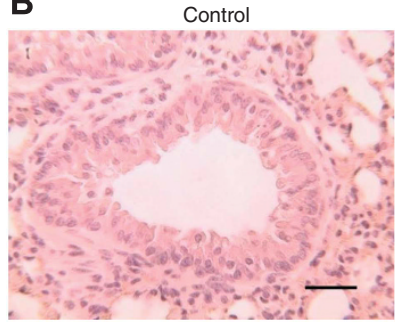

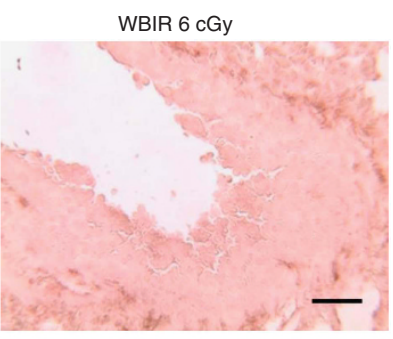

WBIR 5 Gy

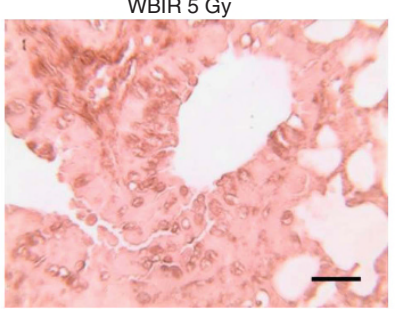

C

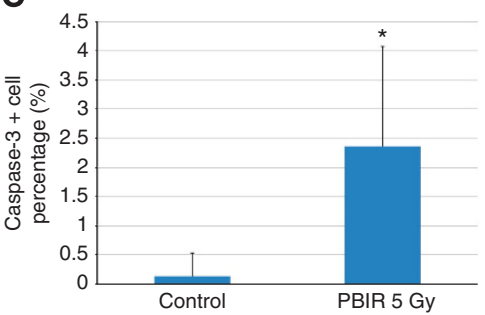

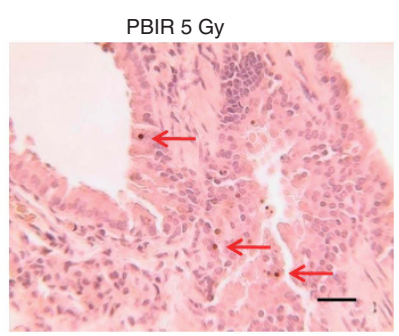

Figure 5. Partial body irradiation (PBIR) induced DNA DSBs and apoptosis in non-targeted lung tissues. (A) 53BP1 was induced in bystander lung bronchial epithelial cells. A representative microscopic field of each treatment group under $\times 40$ magnification is shown. (B) Active caspase-3 staining in control and bystander lung tissues under $\times 40$ magnification. Arrows show positive caspase-3 cells. (C) Quantification of the fraction of positive caspase- 3 cells assessed by microscopy under $\times 40$ magnification. Bar represents $50 \mu \mathrm{m}$. Statistical comparison between control and irradiation groups marked with asterisks ( ${ }^{*} P<0.05$, Student's $t$-test). Error bars for quantification of caspase-3 staining in each group indicate the s.e.m. for 20 independent microscopic fields from three different mice.

induction of COX-2 protein. Both of these isoforms of prostaglandin were increased in bystander lung tissues compared with sham-treated animals (Figures $4 \mathrm{~A}$ and B). Compared with the level in tissues, plasma prostaglandin levels did not show a significant change after PBIR (data not shown).

There is evidence that prostaglandins induce production of reactive oxygen species and oxidative DNA damage such as formation of 8-OHdG (Ichinose et al, 1997). We examined the level of oxidative DNA damage in lung tissues using immunohistochemistry staining of $8-\mathrm{OHdG}$. The WBIR dramatically induced 8-OHdG in the lung tissues (Figure 4C). Likewise, relative to control animals, non-targeted lung tissues in partial bodyirradiated animals showed positive 8 -OHdG staining at $24 \mathrm{~h}$ after irradiation of the lower abdomen. Consistent with the distribution of COX-2 in lung tissues (Figure 3E), 8-OHdG was predominantly located in lung bronchial epithelial cells. Quantification of the staining intensity showed that non-targeted irradiation induced an 8 -fold increase in oxidative DNA damage compared with controls, whereas WBIR with 5 Gy X-rays resulted in a 12-fold increase (Figure 4D).

Lower abdominal irradiation induces DSBs and apoptosis in non-targeted lung tissues. Large-size deletions are always associated with non-homologous end-joining of DNA double strand breaks (DSBs) in cells damaged by various environmental mutagens (Nohmi and Masumura, 2005). We examined DNA DSBs using immunohistochemistry staining of 53BP1 (tumour protein 53 binding protein 1), which is recruited to DNA DSB sites at the DNA damage checkpoint, and is an early indicator of DNA damage repairing events (Wang et al, 2002). The enhancement of $53 \mathrm{BP} 1$ in bystander lung tissues (Figure 5A), especially lung bronchial epithelia, implied induction of DNA DSBs by PBIR within $24 \mathrm{~h}$ after irradiation, whereas WBIR with a scattering dose (6 cGy) did not. Compared with PBIR, WBIR with 5 Gy of X-rays showed more dramatic induction of 53BP1 in lung bronchial tissues (Figure 5A).

Apoptosis is a possible consequence of damaged cells, especially for those cells that sustain severe damage to DNA. Apoptosis in lung tissues was determined using immunohistochemistry staining of activated caspase-3. Compared with the negligible staining level in lung tissues in controls, caspase-3 was significantly elevated in bystander lung tissues at $24 \mathrm{~h}$ after PBIR (Figure 5B). WBIR with a 6-cGy dose of X-rays (simulating a possible scattering dose received by the lung tissues) have similar results as control, and WBIR with a $5 \mathrm{~Gy}$ dose of X-rays induced a higher level of apoptosis compared with that of PBIR (data not shown). The percentage of apoptotic cells in bystander lung tissues increased nearly 18 -fold relative to control lung tissues (from 0.13 to $2.36 \%$ ), as measured under $\times 40$ magnification (Figure $5 \mathrm{C}$ ).

Tissue-dependent induction of COX-2 expression and mutagenesis in the non-targeted tissues after lower abdominal irradiation. We found that induction of COX-2 and mutagenesis was tissue-specific. As previously noted, COX-2 was induced in bystander lungs of both female and male mice with similar kinetics, that is, peaked at $24 \mathrm{~h}$ after PBIR (Figures 3C and D), but with different absolute magnitude. In contrast, non-targeted liver tissues from the same animals did not show induction of COX-2 
A
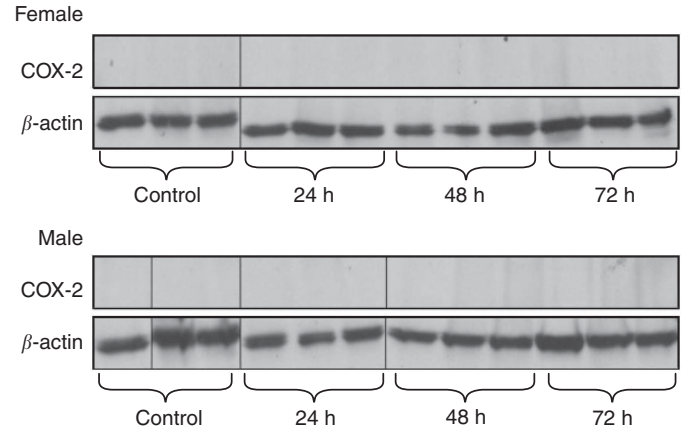
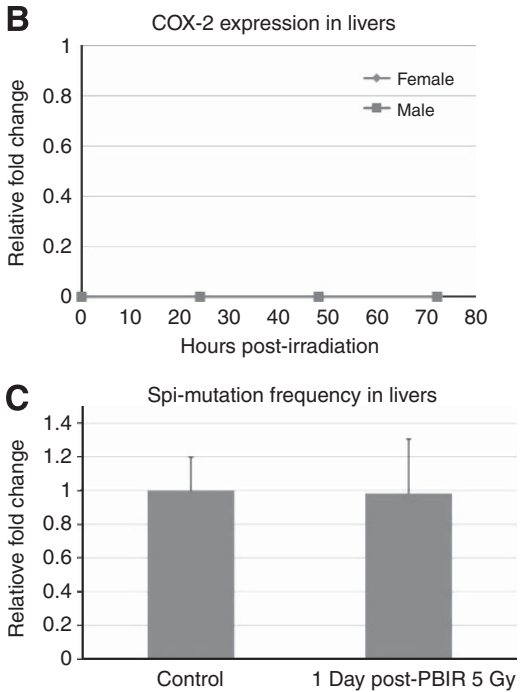

Figure 6. Induction of COX-2 and mutagenesis is tissue dependent. (A) Cyclooxygenase 2 was not induced in bystander liver tissues of female or male animals at a series of time points after PBIR. (B) Quantification of COX-2 protein levels in bystander liver tissues at a series of time points after irradiation. (C) Mutant frequency (MF) by Spi ${ }^{-}$assay in liver tissues of male animals at $24 \mathrm{~h}$ after irradiation. Error bars for quantification of $\mathrm{COX}-2$ expression and relative $\mathrm{Spi}^{-} \mathrm{MF}$ in each group indicate the s.e.m. for three independent animals.

expression or mutagenesis. The COX-2 levels did not change in liver tissues up to $72 \mathrm{~h}$ after treatment (Figures $6 \mathrm{~A}$ and $\mathrm{B}$ ). $\mathrm{The} \mathrm{Spi}^{-}$MF in bystander liver tissues was also not significantly different from that in liver tissues of the control group (Figure 6C). This contrasts with the dramatic induction of both COX-2 and mutagenesis in lung tissues at $24 \mathrm{~h}$ after PBIR (Figures $2 \mathrm{~A}$ and $6 \mathrm{C})$.

\section{DISCUSSION}

In this study, we used gpt delta transgenic mouse model to study radiation-induced mutagenesis in non-targeted tissues after PBIR. In contrast to previous in vivo bystander studies based on irradiation of half the body of an animal (Mancuso et al, 2008), we only irradiated a small area $(1 \mathrm{~cm} \times 1 \mathrm{~cm})$ of otherwise fully shielded mice (Figure 1A), simulating radiotherapy-relevant conditions. We examined short-term bystander responses in non-irradiated organs (lung and liver) of these partial bodyirradiated mice. The protein level of COX-2 peaked at $24 \mathrm{~h}$ after irradiation (Figure 3B), which resulted in the concurrent increase of prostaglandin production and oxidative DNA damage in bystander lung tissues (Figure 4). The COX-2 is found to be overexpressed in many types of epithelial tumours, such as lung (Ramalingam and Belani, 2004), breast (Bundred and Barnes, 2005) and thymus (Rieker et al, 2006). Chronic inflammation with overexpression of COX-2 is regarded as a potential risk for tumorigenesis (Wang et al, 2005). Interestingly, we found that COX-2 overexpression was predominantly located in bystander bronchial epithelial cells after lower abdominal irradiation (Figures $3 \mathrm{E}$ and $\mathrm{F}$ ). In this study, a single dose of radiation induced COX-2 and mutagenesis up to $24 \mathrm{~h}$ after irradiation (Figures 2 and $3 \mathrm{~A}$ ). However, during conventional radiotherapy, most cancer patients are given fractionated irradiation. The typical treatment plan of fractionated radiotherapy for adult patients is 1.8 to 2 Gy per day, 5 days per week for 5-7 weeks continuously. Therefore, we need to consider the possibility that fractionated irradiation may induce an upregulation of COX-2 within $24 \mathrm{~h}$ after treatment and maintain a high level of COX-2 in non-targeted tissues/organs during the course of treatment. A consistent overexpression of COX-2 may result in chronic inflammation, which could pose a long-term risk for mutagenesis and carcinogenesis in long-term cancer survivors. This may be a particular concern for patients with a radiosensitive genetic background.

In this study, different types of mutation were identified in bystander lung tissues. We found oxidative DNA damage, particularly in lung bronchial epithelial cells (Figure 4C). Besides oxidative DNA damage, large-size mutations were identified in bystander lung tissue, reaching a peak at $24 \mathrm{~h}$ after treatment and decreasing thereafter (Figure 2 and Table 1). The data show the activation of apoptosis in non-targeted lung tissues after PBIR (Figure 5B), which suggests that bystander tissues mount a protective response, leading to reduction of mutations and prevention of further damage in bystander lung at $24 \mathrm{~h}$ after irradiation.

We have also shown there is no significant gender dependence for induction of COX-2 in bystander lung tissue. However, the induction of COX-2 and mutagenesis in non-targeted organs appears to occur in a tissue-specific pattern. It was detected in bystander lung but not in liver tissue. Tissue-specific bystander effects have also been shown in other in vivo systems. Ilnytskyy et al have shown that PBIR induced different epigenetic responses in bystander organs such as skin and spleen (Ilnytskyy et al, 2009), although a similar response was induced in the same organism by acute or fractionated exposure.

There are several important issues that still need to be addressed, such as how irradiation of lower abdomen induces COX-2 and mutagenesis in out-of-field lung tissues, why COX-2 is predominantly induced in lung bronchial epithelial cells but not stromal cells, and why induction of COX-2 appears to occur in a tissue-dependent manner. For the initiation of bystander responses in non-targeted lung tissues, it is likely that some signal molecules such as cytokine(s) are released from the irradiated area and circulate to non-targeted tissues to induce responses. Alternatively, some irradiated cells, such as macrophages, lymphocytes or neutrophils, may circulate to non-targeted tissues and initiate the downstream signalling events, leading to induction of COX-2 expression in bystander lung tissues. On the basis of these results in vitro and in vivo, further studies of the mechanism(s) of radiation induced bystander effects in vivo, especially induction of COX-2 and mutagenesis, are needed. 


\section{ACKNOWLEDGEMENTS}

This work was supported by funding from the National Institutes of Health grants CA 49062, ES 12888, NIH Resource Centre grant RR 11623 and Environmental Center grant ES 09089.

\section{REFERENCES}

Bundred NJ, Barnes NL (2005) Potential use of COX-2-aromatase inhibitor combinations in breast cancer. Br J Cancer 93(Suppl 1): S10-S15.

Calaf GM, Echiburu-Chau C, Zhao YL, Hei TK (2008) BigH3 protein expression as a marker for breast cancer. Int J Mol Med 21: 561-568.

Chai Y, Hei TK (2008) Radiation induced bystander effect in vivo. Acta Med Nagasaki 53: S65-S69.

Famaey JP (1997) In vitro and in vivo pharmacological evidence of selective cyclooxygenase- 2 inhibition by nimesulide: an overview. Inflamm Res 46: $437-446$.

Gardner B, Zhu LX, Sharma S, Tashkin DP, Dubinett SM (2003) Methanandamide increases COX-2 expression and tumor growth in murine lung cancer. FASEB J 17: 2157-2159.

Hei TK (2006) Cyclooxygenase-2 as a signaling molecule in radiation-induced bystander effect. Mol Carcinog 45: 455-460.

Horiguchi M, Masumura KI, Ikehata H, Ono T, Kanke Y, Nohmi T (2001) Molecular nature of ultraviolet B light-induced deletions in the murine epidermis. Cancer Res 61: 3913-3918.

Ichinose T, Yajima Y, Nagashima M, Takenoshita S, Nagamachi Y, Sagai M (1997) Lung carcinogenesis and formation of 8-hydroxydeoxyguanosine in mice by diesel exhaust particles. Carcinogenesis $\mathbf{1 8}$ 185-192.

Ilnytskyy Y, Koturbash I, Kovalchuk O (2009) Radiation-induced bystander effects in vivo are epigenetically regulated in a tissue-specific manner. Environ Mol Mutagen 50: 105-113.

Ivanov VI, Zhou H, Ghandhi SA, Karasic TB, Yaghoubian B, Amundson SA, Hei TK (2010) Radiation-induced bystander signaling pathways in human fibroblasts: a role for interleukin-33 in the signal transmission. Cell Signal 22: 1076-1087.

Kiatchoosakun S, Kirkpatrick D, Hoit BD (2001) Effects of tribromoethanol anesthesia on echocardiographic assessment of left ventricular function in mice. Comp Med 51: 26-29.

Lee HC, Shibata H, Ogawa S, Maki K, Ikuta K (2005) Transcriptional regulation of the mouse IL-7 receptor alpha promoter by glucocorticoid receptor. J Immunol 174: 7800-7806.

Mancuso M, Pasquali E, Leonardi S, Tanori M, Rebessi S, Di Majo V, Pazzaglia S, Toni MP, Pimpinella M, Covelli V, Saran A (2008) Oncogenic bystander radiation effects in Patched heterozygous mouse cerebellum. Proc Natl Acad Sci USA 105: 12445-12450.

Masumura K, Kuniya K, Kurobe T, Fukuoka M, Yatagai F, Nohmi T (2002) Heavy-ion-induced mutations in the gpt delta transgenic mouse: comparison of mutation spectra induced by heavy-ion, $\mathrm{X}$-ray, and gamma-ray radiation. Environ Mol Mutagen 40: 207-215.

Masumura K, Totsuka Y, Wakabayashi K, Nohmi T (2003) Potent genotoxicity of aminophenylnorharman, formed from non-mutagenic norharman and aniline, in the liver of gpt delta transgenic mouse. Carcinogenesis 24: 1985-1993.

Mitchell JA, Belvisi MG, Akarasereenont P, Robbins RA, Kwon OJ, Croxtall J, Barnes PJ, Vane JR (1994) Induction of cyclo-oxygenase-2 by cytokines in human pulmonary epithelial cells: regulation by dexamethasone. Br J Pharmacol 113: 1008-1014.
Morgan GW, Breit SN (1995) Radiation and the lung: a reevaluation of the mechanisms mediating pulmonary injury. Int J Radiat Oncol Biol Phys 31: 361-369.

Nohmi T, Katoh M, Suzuki H, Matsui M, Yamada M, Watanabe M, Suzuki M, Horiya N, Ueda O, Shibuya T, Ikeda H, Sofuni T (1996) A new transgenic mouse mutagenesis test system using Spi- and 6-thioguanine selections. Environ Mol Mutagen 28: 465-470.

Nohmi T, Masumura K (2004) Gpt delta transgenic mouse: a novel approach for molecular dissection of deletion mutations in vivo. Adv Biophys $\mathbf{3 8}$ : 97-121.

Nohmi T, Masumura K (2005) Molecular nature of intrachromosomal deletions and base substitutions induced by environmental mutagens. Environ Mol Mutagen 45: 150-161.

Ouyang W, Ma Q, Li J, Zhang D, Ding J, Huang Y, Xing MM, Huang C (2007) Benzo[a]pyrene diol-epoxide (B[a]PDE) upregulates COX-2 expression through MAPKs/AP-1 and IKKbeta/NF-kappaB in mouse epidermal Cl41 cells. Mol Carcinog 46: 32-41.

Prise KM, Belyakov OV, Folkard M, Michael BD (1998) Studies of bystander effects in human fibroblasts using a charged particle microbeam. Int J Radiat Biol 74: 793-798.

Ramalingam S, Belani CP (2004) Cyclooxygenase-2 inhibitors in lung cancer. Clin Lung Cancer 5: 245-253.

Rieker RJ, Joos S, Mechtersheimer G, Blaeker H, Schnabel PA, Morresi-Hauf A, Hecker E, Thomas M, Dienemann H, Schirmacher P, Kern MA (2006) COX-2 upregulation in thymomas and thymic carcinomas. Int J Cancer 119: 2063-2070.

Salmenkivi K, Haglund C, Ristimaki A, Arola J, Heikkila P (2001) Increased expression of cyclooxygenase-2 in malignant pheochromocytomas. J Clin Endocrinol Metab 86: 5615-5619.

Sankaranarayanan K (1991) Ionizing radiation and genetic risks. II. Nature of radiation-induced mutations in experimental mammalian in vivo systems. Mutat Res 258: 51-73.

Song S, Lippman SM, Zou Y, Ye X, Ajani JA, Xu XC (2005) Induction of cyclooxygenase- 2 by benzo[a]pyrene diol epoxide through inhibition of retinoic acid receptor-beta 2 expression. Oncogene 24: $8268-8276$.

Sudbo J, Ristimaki A, Sondresen JE, Kildal W, Boysen M, Koppang HS, Reith A, Risberg B, Nesland JM, Bryne M (2003) Cyclooxygenase-2 (COX-2) expression in high-risk premalignant oral lesions. Oral Oncol 39: 497-505.

Wang B, Matsuoka S, Carpenter PB, Elledge SJ (2002) 53BP1, a mediator of the DNA damage checkpoint. Science 298: 1435-1438.

Wang W, Bergh A, Damber JE (2005) Cyclooxygenase-2 expression correlates with local chronic inflammation and tumor neovascularization in human prostate cancer. Clin Cancer Res 11: 3250-3256.

Zhou H, Ivanov VN, Gillespie J, Geard CR, Amundson SA, Brenner DJ, Yu Z, Lieberman HB, Hei TK (2005) Mechanism of radiation-induced bystander effect: role of the cyclooxygenase-2 signaling pathway. Proc Natl Acad Sci USA 102: 14641-14646.

Zhou H, Ivanov VN, Lien YC, Davidson M, Hei TK (2008) Mitochondrial function and nuclear factor-kappaB-mediated signaling in radiationinduced bystander effects. Cancer Res 68: 2233-2240.

Zhou H, Randers-Pehrson G, Waldren CA, Vannais D, Hall EJ, Hei TK (2000) Induction of a bystander mutagenic effect of alpha particles in mammalian cells. Proc Natl Acad Sci USA 97: 2099-2104.

This work is published under the standard license to publish agreement. After 12 months the work will become freely available and the license terms will switch to a Creative Commons AttributionNonCommercial-Share Alike 3.0 Unported License. 